\title{
WUJUD AKULTURASI ARSITEKTUR PADA ASPEK FUNGSI, BENTUK, DAN MAKNA BANGUNAN GEREJA KRISTEN PNIEL BLIMBINGSARI DI BALI
}

\author{
Stephanie Arvina Yusuf \\ Magister Arsitektur, Program Pascasarjana, Universitas Katolik Parahyangan, Bandung, Indonesia \\ Email: steviarvina@gmail.com
}

\begin{abstract}
Abstrak
Saat ajaran Kristen Protestan masuk ke Desa Blimbingsari, Bali merupakan awal proses percampuran antara budaya lokal dan pendatang. Percampuran antara budaya lokal dengan pendatang ini membentuk akulturasi dalam wujud arsitektur. Hal ini terwujud pada arsitektur komplek Gereja Kristen Pniel Blimbingsari, Bali. Bentuk bangunan Gereja bukan lagi seperti gambaran pada umumnya dan memiliki bentuk yang unik dibandingkan bangunan Gereja lain di Pulau Bali. Hasil studi menunjukkan bahwasannya Gereja Kristen Pniel Blimbingsari mengalami proses akulturasi pada arsitektur bangunan dan lingkungan tapaknya. Studi ini bertujuan untuk mengungkap wujud akulturasi yang terjadi dilihat dari aspek fungsi, bentuk dan makna bangunannya. Metoda yang digunakan dalam penelitian ini yakni bersifat deskriptif, analitis, dan intepretatif berdasarkan studi di lapangan dan bukti empiris. Pendekatan yang dilakukan berlandas pada teori Konsep Asta Kosala Kosali Bali, Arsitektur Gereja Kristen, dan archetypes dalam arsitektur yang dikolaborasikan dengan aspek fungsi, bentuk, dan makna arsitektur. Hasil studi menyimpulkan bahwasannya terjadi relasi antara fungsi, bentuk dan makna yang menyiratkan dominasi pada wujud arsitektur yang terakulturasi. Aspek dominan dalam arsitektur pada penelitian ini merupakan hasil dari intepretasi percampuran dua aspek/konsep yang berbeda dalam satu wujud arsitektur. Konsep aristektur tradisonal Bali (Asta Kosala Kosali) memiliki peran yang dominan dalam membentuk Gereja Kristen Pniel Blimbingsari tanpa mengubah pakem liturgi dan kebutuhan pada fungsi suatu komplek Gereja Kristen Protestan. Studi ini diharapkan dapat memberikan manfaat sebagai rujukan kasus serupa yakni akulturasi dan dapat menyumbangkan pengetahuan dalam ranah arsitektur.
\end{abstract}

Kata kunci: Akulturasi, arsitektur, gereja, fungsi, bentuk, makna.

\begin{abstract}
Title: Aspects of Architecture Infrastructures Acculturation Function, Form and the Meaning of the Christian Church Building Pniel Blimbingsari in Bali

When culture and Christianity entered Blimbingsari Village, Bali was the beginning of combination between local and migrant culture. Combination of both cultures became an acculturation in architectural form. It is materialized in architecture of Gereja Kristen Pniel Blimbingsari, Bali. Church building form was no longer as an idea generally with the characteristics soaring roof, Gothic architecture style, and so on. Preliminary studies indicate that Gereja Kristen Pniel Blimbingsari through the acculturation process that affect in architectural form and religious rituals. This study aims to reveal a form of acculturation occurs seen from the aspect of function, form and meaning of the building. The method in this research that is descriptive, analytical, and interpretative based on field studies and empirical evidence. This approach taken grounded in cultural theory and archetypes in architecture which collaborated with the aspect of function, form, and meaning of architecture. The study concluded that occur relations between function, form and meaning that implies domination in
\end{abstract}


the form of architecture acculturated. The study concludes that there was a relation between function, form and meaning which implies the dominance in the form of architecture that acculturated. Dominance in this study is as a result of interpretation From the analysis conducted. The concept of Asta Kosala Kosali have a dominant role in shaping the architectural form of acculturation Gereja Kristen Pniel Blimbingsari. The study is expected to benefit as a reference to a similar case that acculturation and can contribute knowledge in the realm of architecture.

Keywords: Acculturation, architecture, church, function, form, meaning.

\section{Pendahuluan}

Gereja Kristen Pniel Blimbingsari merupakan salah satu bangunan yang telah dipengaruhi oleh budaya setempat yakni Bali melalui proses akulturasi. Konsep lokal yakni Asta Kosala Kosali menjadi pakem yang terus dipertahankan masyarakat Bali dalam mendirikan sebuah bangunan peribadatan, sedangkan bangunan Gereja juga memiliki pakem tersendiri dalam memenuhi kebutuhan fungsi bangunannya. Hal ini terjadi pada Komplek Gereja Kristen Pniel Blimbingsari yang memiliki wujud arsitektur yang unik dan menarik dibandingkan komplek Gereja lainnya di pulau Bali.

Hasil studi mengenai wujud arsitektur dan aspek budaya terhadap kondisi faktual menunjukkan bahwasannya Gereja Kristen Pniel Blimbingsari mengalami proses akulturasi pada arsitektur bangunannya secara keseluruhan. Hal ini mendorong untuk merunut ke belakang kepada perpaduan dan penyesuaian diri yang terjadi antara budaya lokal dan budaya asing. Kajian tentang akulturasi budaya dan arsitektur yang mempengaruhi bentukan fisik dan non-fisik ini akan menarik untuk diangkat dan ditelaah. Adanya keterkaitan konteks budaya dan lingkungan setempat menjadikan suatu wujud arsitektur memiliki ciri karakter tersendiri di tiap-tiap daerahnya.

Aspek fungsi, bentuk, dan makna tentu tidak terlepas dari suatu gubahan arsitektur. Maka ketiga aspek ini menjadi acuan dalam mengupas fenomena yang ada. Bangunan ditelaah secara aspek fisik (bentuk) dan non-fisik (fungsi) yang terkait dengan makna sebagai hasil interpretasi pengamat. Hasil interpretasi ini menyiratkan dominasi yang terjadi pada wujud arsitektur Gereja Kristen Pniel Blimbingsari sebagai hasil akulturasi. Dalam hal ini, dominasi merujuk pada konsep yang memiliki pengaruh kuat dalam wujud arsitektur Gerejanya.

Objek yang diteliti secara spesifik adalah wujud arsitektur Gereja Kristen Pniel Blimbingsari yang berada di Desa Blimbingsari, Bali. Aspek budaya lokal dan pendatang yakni budaya dan agama dalam konsep Kristen juga menjadi salah satu hal yang diamati mengingat terjadinya akulturasi pada objek teliti. Bangunan dikupas secara lebih detail berdasarkan elemen-elemen pelingkupnya, menguraikan elemen bangunan berdasarkan konsep dasarnya agar mendapatkan esensi dasar dari karakter bangunan tersebut untuk mengungkap akulturasi yang terjadi pada arsitekturnya. Penempatan tiap ornamen menjadi saling melengkapi dan memiliki makna yang tidak bertentangan. 
Penelitian ini bersifat kualitatif yaitu mengungkap salah satu fenomena akulturasi budaya dan arsitektur yang terjadi pada bangunan suci keagamaan.

\section{Metode Penelitian}

\section{Kasus Studi}

Objek penelitian secara spesifik ialah komplek Gereja Kristen Pniel Blimbingsari yang terdapat di Desa Blimbingsari, Kecamatan Jembrana, Bali. Gereja ini merupakan gereja tertua yang berada di Desa Blimbingsari sebagai desa yang mayoritas penduduknya beragama Kristen Protestan. Gereja Kristen Pniel
Blimbingsari tersebut mendapat sentuhan dari Konsep Asta Kosala Kosali Bali. Keunikan yang terdapat pada Gereja Pniel ini menarik perhatian untuk meneliti mengenai bagaimana tata ruang, aturan Gereja. Seperti penyusunan bangunan gereja Blimbingsari tersebut sebagian besar diadaptasi dari tata cara mendirikan Pura. Sentuhan ornamen dan ukiranukiran yang terdapat pada bangunan Gereja tersebut, serta tata letak ruang pada interior gereja tersebut mencerminkan terjadinya akulturasi dengan budaya lokal (Bali) yakni Konsep Asta Kosala Kosali.
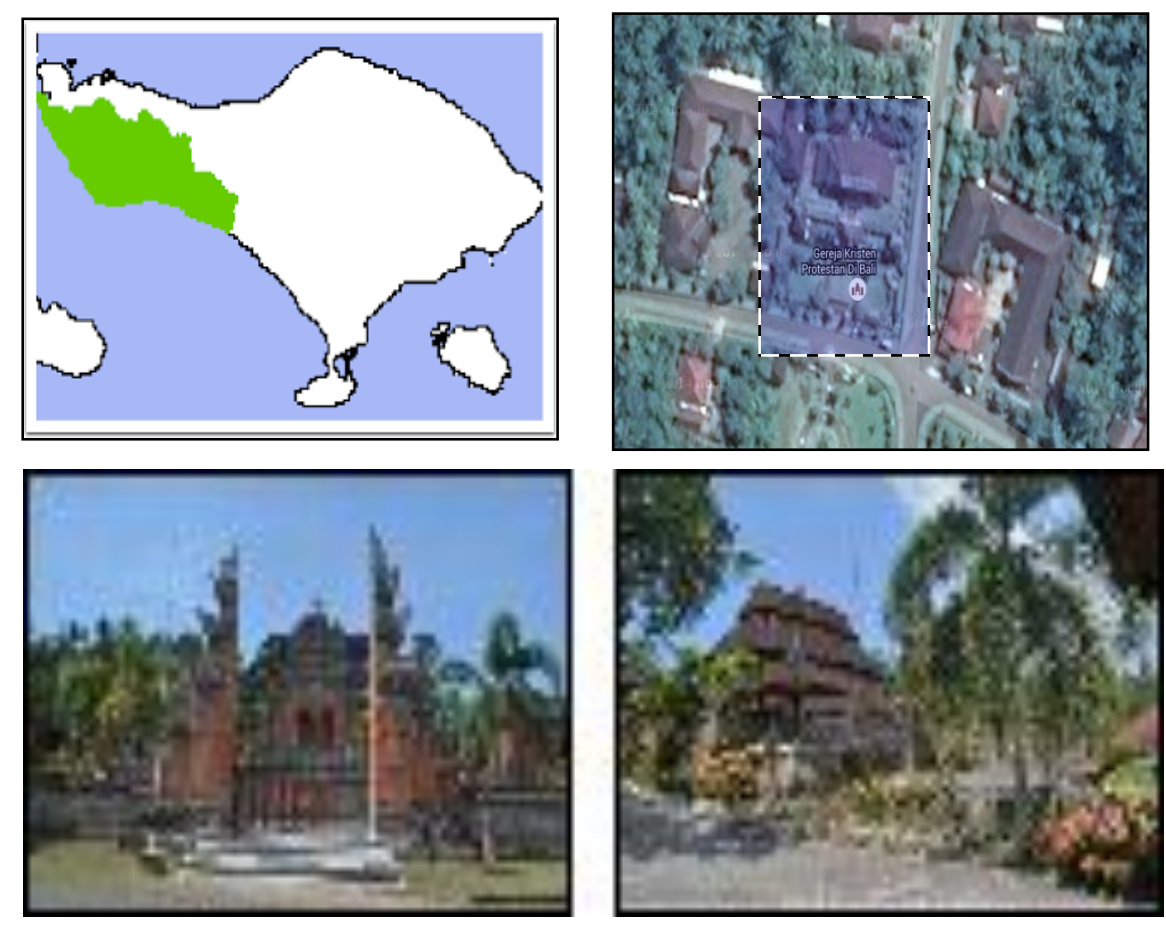

Gambar 1. Gereja Kristen Pniel Blimbingsari, Bali

Sumber: Dokumentasi Penulis, 2016

\section{Langkah Anlisa}

Langkah analisa dalam penelitian ini dibagi menjadi tiga yakni :
1. Analisa awal yakni Gereja Kristen Pniel Blimbingsari ditelaah melalui aspek fisiknya. Aspek fisik terkait dengan aspek bentuk arsitekturnya 
yang melingkupi orientasi, tata massa, bentukan arsitektur (fasad), elemen arsitektur, pola tata ruang dalam bangunan, dan ragam hias.

2. Tahap kedua yakni Gereja Kristen Pniel Blimbingsari ditelaah melalui aspek non-fisiknya. Aspek non-fisik terkait dengan aspek fungsi di dalamnya. Fungsi secara umum yakni ritual keagamaan Gereja.

3. Tahap ketiga yakni aspek fisik dan non-fisik Gereja Kristen Pniel Blimbingsari disejajarkan dan saling terintegrasi untuk memahami aspek makna sebagai bagian dari diagram aspek fungsi, bentuk, dan makna dalam arsitektur. Dengan demikian maka dapat dengan mudah memahami aspek yang dominan pada wujud arsitektur Gereja Kristen Pniel Blimbingsari sebagai nterpretasi dari aspek makna yang terkandung.

Berikut pokok-pokok analisis yang dipetakan dalam skema di bawah ini:

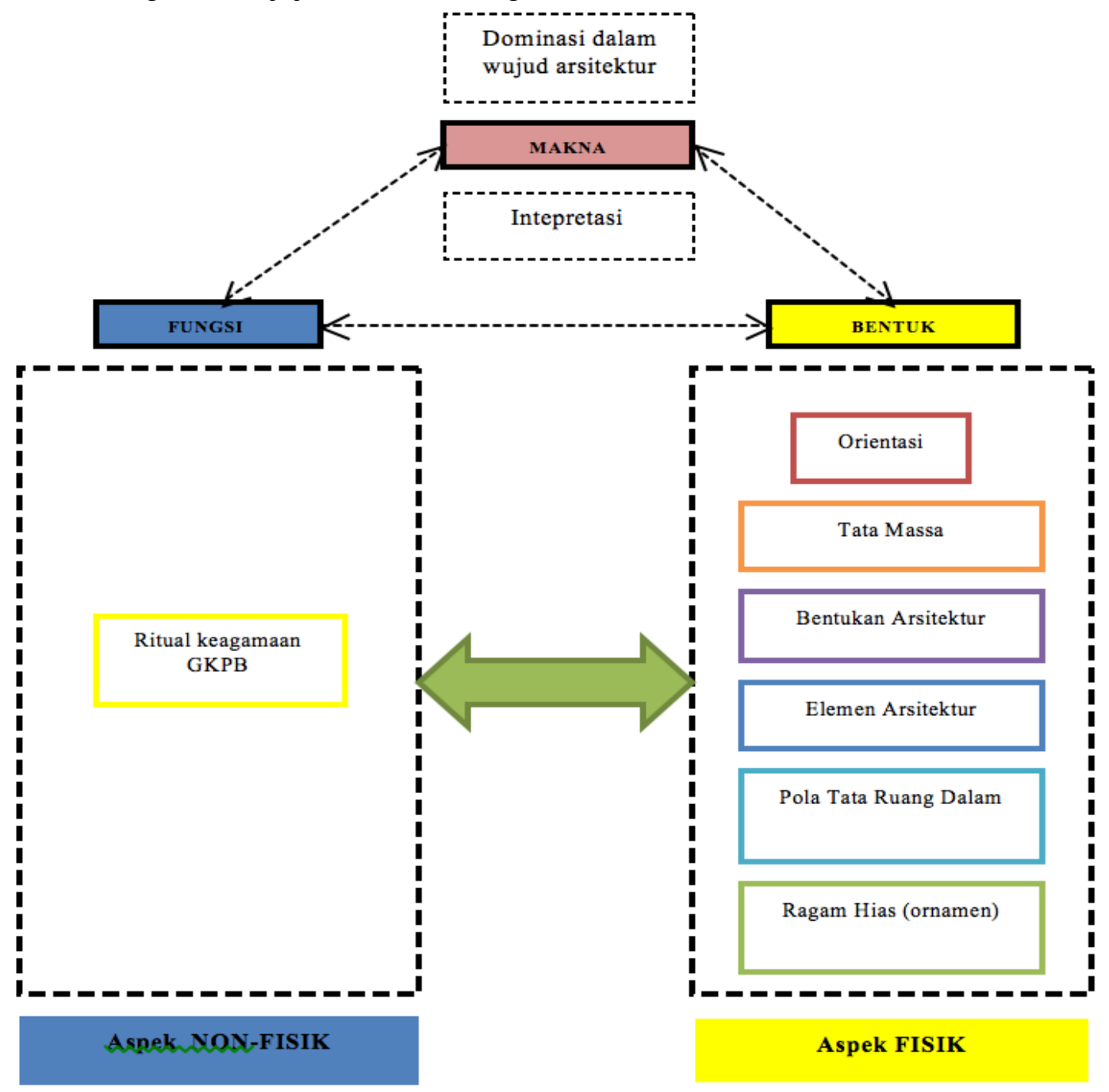

Gambar 2. Skema pokok analisis akulturasi arsitektur gereja Kristen Pniel Blimbingsari, Bali Sumber: Hasil Analisis, 2016 


\section{Hasil Penelitian}

\section{Analisis Aspek Fisik pada Arsitektur Gereja Kristen Pniel Blimbingsari, Bali}

a. Orientasi bangunan

Tabel 1. Analisis kompleks gereja Kristen Pniel Blimbingsari, Bali

\begin{tabular}{|c|c|c|}
\hline Konsep Asta Kosala Kosali & $\begin{array}{c}\text { Arsitektur Gereja Kristen } \\
\text { Pniel Blimbingsari, Bali }\end{array}$ & Arsitektur Gereja \\
\hline $\begin{array}{l}\text { Orientasi kosmologi terbagi } \\
\text { menjadi tiga yakni, Sumbu Tri } \\
\text { Loka, Sumbu Ritual, dan Sumbu } \\
\text { Natural. Sumbu Ritual yaitu } \\
\text { kangin (terbit matahari) dan kauh } \\
\text { (terbenam matahari). Tapak } \\
\text { komplek bangunan peribadatan } \\
\text { baiknya memanjang utara selatan } \\
\text { atau dipahami dalam sumbu } \\
\text { natural (gunung dan laut). }\end{array}$ & $\begin{array}{lrr}\text { Penerapan } & \text { konsep } & \text { Sumbu } \\
\text { Ritual dan } & \text { Sumbu } & \text { Natural } \\
\text { dilakukan komplek } & \text { Gereja } \\
\text { Kristen Pniel Blimbingsari, } \\
\text { Bali. }\end{array}$ & $\begin{array}{l}\text { Pada arsitektur Gereja tidak } \\
\text { ditekankan arah hadap atau } \\
\text { orientasi dari bangunan gereja } \\
\text { itu sendiri. Pada pertimbangan } \\
\text { awal, gereja lebih menekankan } \\
\text { pada fungsi untuk melakukan } \\
\text { peribadatan. }\end{array}$ \\
\hline \multicolumn{3}{|c|}{$\begin{array}{l}\text { Kesimpulan : Arsitektur komplek Gereja Kristen Pniel Blimbingsari menerapkan konsep orientasi } \\
\text { yang bertolak dari konsep Asta Kosala Kosali. Penerapan konsep ini tidak melanggar pakem Gereja. } \\
\text { Penekanan orientasi terhadap sumbu tertentu tidak ditekankan dalam konsep arsitektur Gereja. }\end{array}$} \\
\hline
\end{tabular}

Sumber: Hasil Analisis, 2016 
b. Tata massa

Tabel 2. Analisis tata massa komplek gereja Kristen Pniel Blimbingsari, Bali

\begin{tabular}{|c|c|c|}
\hline Konsep Asta Kosala Kosali & $\begin{array}{c}\text { Arsitektur Gereja Kristen Pniel } \\
\text { Blimbingsari, Bali }\end{array}$ & Arsitektur Gereja \\
\hline $\begin{array}{lr}\text { Pembangian } & \text { zoning } \\
\text { berdasarkan dengan } & \text { prinsip } \\
\text { Tri Angga. Tri } & \text { Angga } \\
\text { memperlihatkan } & \text { tiga } \\
\text { tingkatan yakni } & \text { Utama } \\
\text { Mandala, Madya Mandala, } & \text { Man } \\
\text { dan Nista Mandala atau yang } \\
\text { dikenal dengan Jaba, Jaba } \\
\text { Jero, Dan Jero. Konsep } \\
\text { hirarkial tersebut berpengaruh } \\
\text { pada tata } \\
\text { bangunannya. }\end{array}$ & $\begin{array}{l}\text { Penerapan konsep Tri Angga sebagai } \\
\text { pembagi zoning. Dinding panyeker } \\
\text { Kori Agung sebagai pembatas antar } \\
\text { zoning diterapkan pada komplek } \\
\text { Gereja Kristen Pniel Blimbingsari, } \\
\text { Bali. }\end{array}$ & $\begin{array}{l}\text { Pada arsitektur Gereja tetap } \\
\text { diberlakukan penggunaan } \\
\text { dinding pembatas antara } \\
\text { komplek gereja dengan } \\
\text { lingkungan luar. Hal ini } \\
\text { dilakukan untuk membatasi } \\
\text { lingkup komplek gereja. } \\
\text { Pembagian zoning dilakukan } \\
\text { untuk tingkat kesakralan } \\
\text { gereja, akan tetapi tidak ada } \\
\text { dinding sebagai pembatas } \\
\text { antar zona. }\end{array}$ \\
\hline
\end{tabular}

Kesimpulan : Arsitektur GKPB menerapkan prinsip zoning Tri Angga yang selaras dengan konsep orientasnya. Penggunaan dinding pembatas dilakukan guna mempertegas keberadaan komplek gereja terhadap lingkungannya. Penggunaan dinding pembatas panyeker dan Kori Agung di sesuaikan dengan konsep arsitektur tradisional Bali menggunakan ragam hias ukiran khas Bali. (Tidak mengubah esensi/ maknanya)

Sumber: Hasil Analisis, 2016

Berikut gambaran pembagian zona pada Komplek Gereja Kristen Pniel Blimbingsari Bali beserta tatanan massanya :

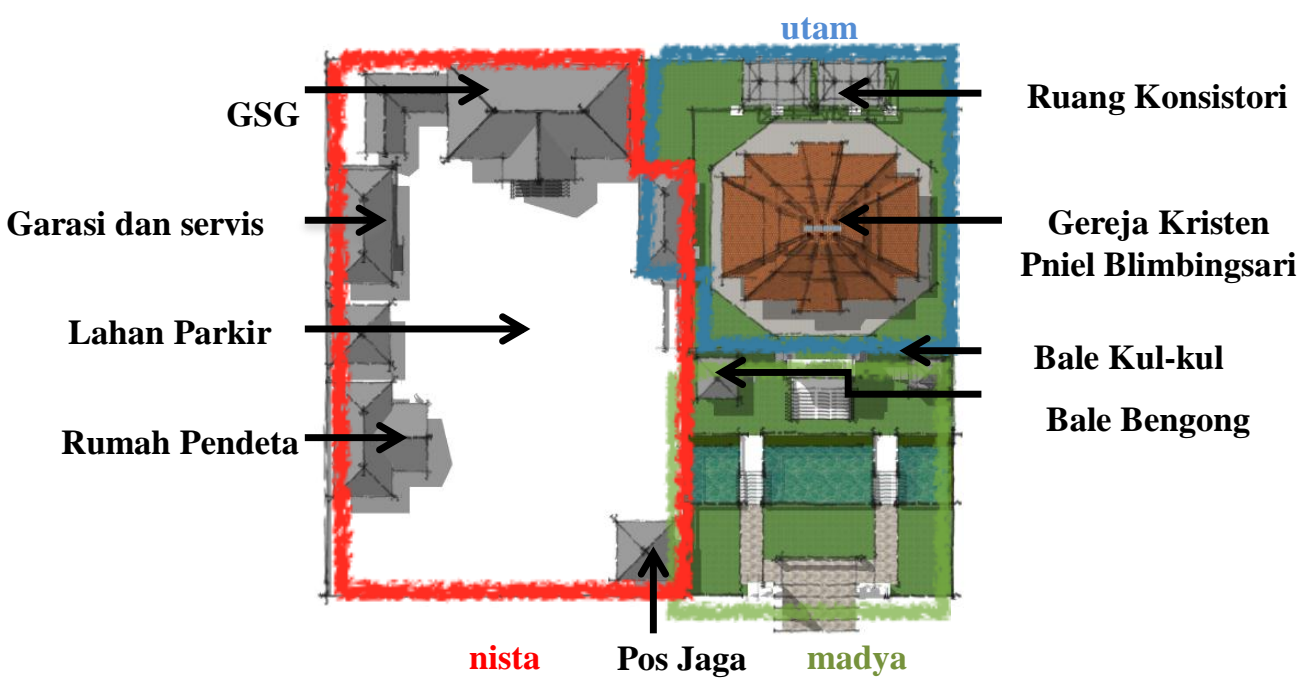

Gambar 3. Pembagian zoning dan tata massa komplek gereja Kristen Pniel Blimbingsari, Bali Sumber: Hasil Analisis, 2016 
Tabel 3. Analisis tata massa pada zona utama komplek gereja Kristen Pniel Blimbingsari, Bali

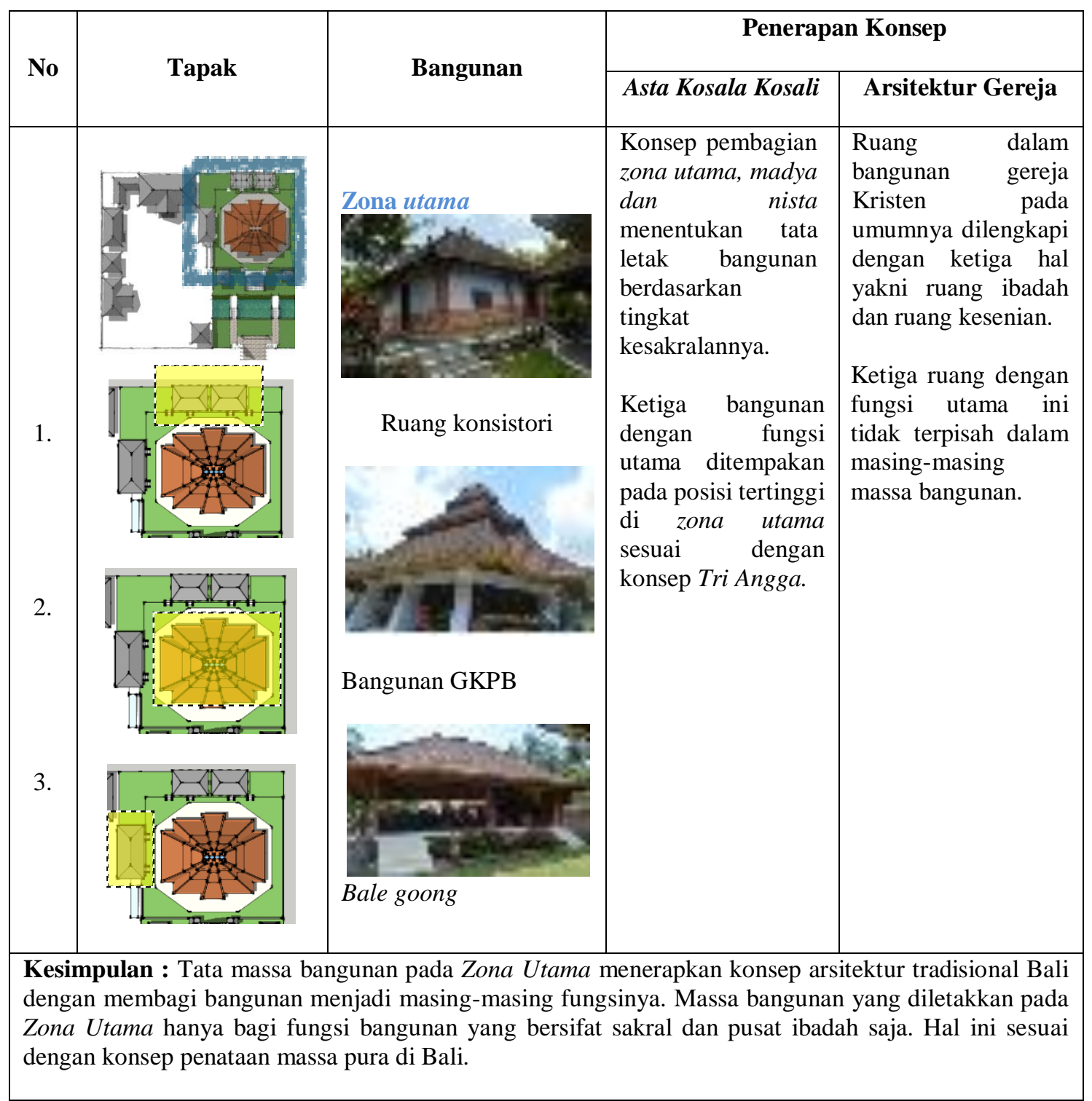

Sumber: Hasil Analisis, 2016

Bangunan gereja terdapat pada posisi tertinggi dalam tapak komplek GKPB. Hal ini dikarenakan fungsi bangunan gereja sebagai pusat tempat ibadah dan memiliki nilai paling sakral. Bangunan gereja, Bale Goong, dan ruang konsistori ketiganya memiliki peran penting dalam keberlangsungan ibadah atau ketika perjamuan maupun kebaktian gereja. Bale Goong berfungsi sebagai ruang kesenian Gereja. 
Tabel 4. Analisis tata massa pada zona madya komplek gereja Kristen Pniel Blimbingsari, Bali

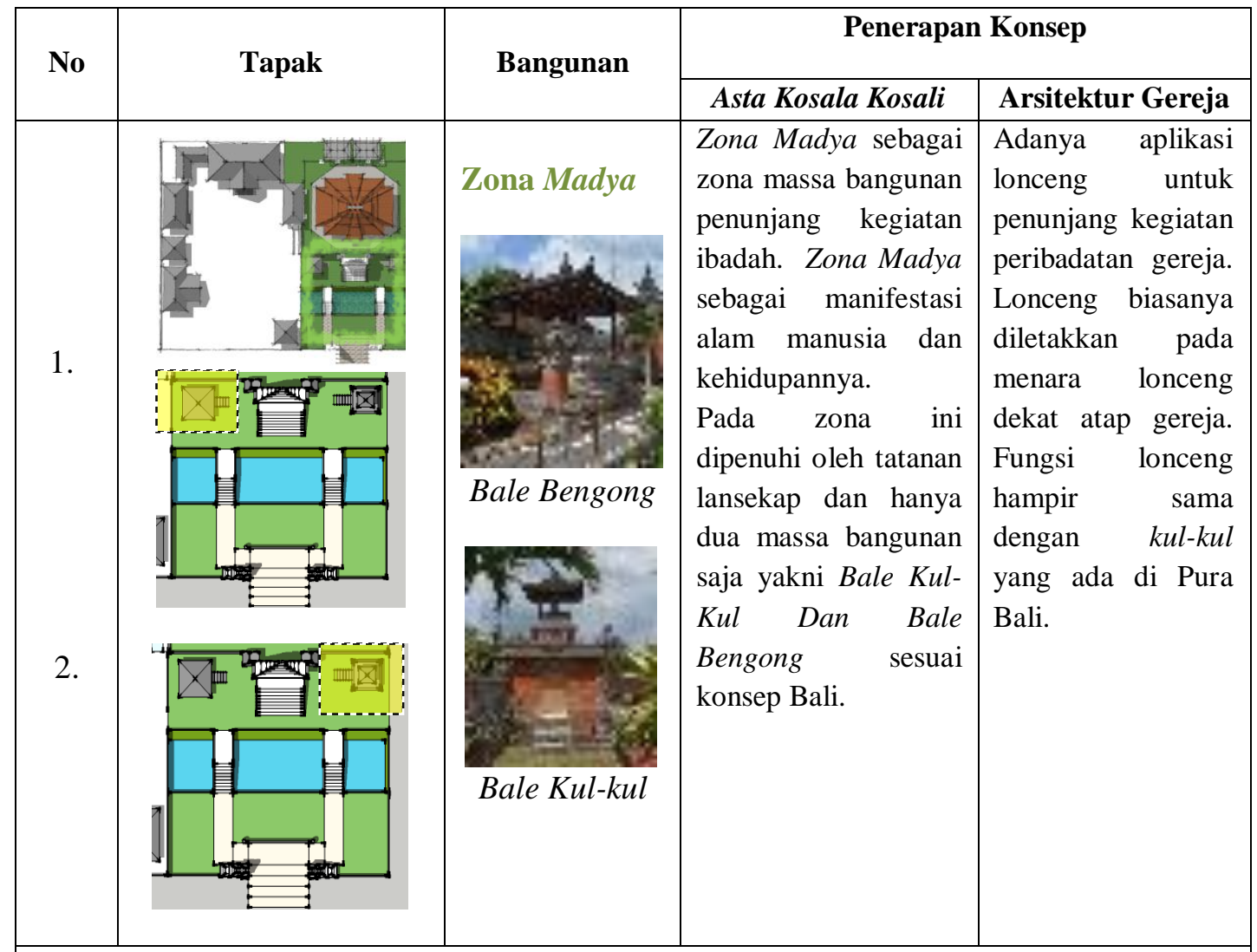

Kesimpulan : Zona Madya komplek GKPB menerapkan konsep Asta Kosala Kosali dan dilengkapi dengan bangunan penunjang (Bale Kul-Kul dan Bale Bengong) yang fungsinya di sesuai dengan kebutuhan gereja juga tidak terlepas dari konsep bangunan tradisional itu sendiri.

Sumber: Hasil Analisis, 2016

Zona Madya memiliki fungsi penunjang kegiatan peribadatan dalam konsep arsitektur tradisional Bali. Bangunan yang berada pada Zona Madya yakni Bale Bengong dan Bale Kul-kul juga Kori Agung sebagai pintu masuk menuju Zona Utama. Pada Zona Madya ini dibatasi oleh dinding panyeker juga dilengkapi Candi Bentar sebagai pintu masuk menuju Zona Madya yang berbatasan langsung dengan jalan. Dinding aling-aling dilengkapi dengan ukiran khas Bali dan hal ini memiliki fungsinya sesuai filosofi sebagai penangkal energi negatif yang akan masuk ke komplek Gereja Kristen Pniel Blimbingsari.

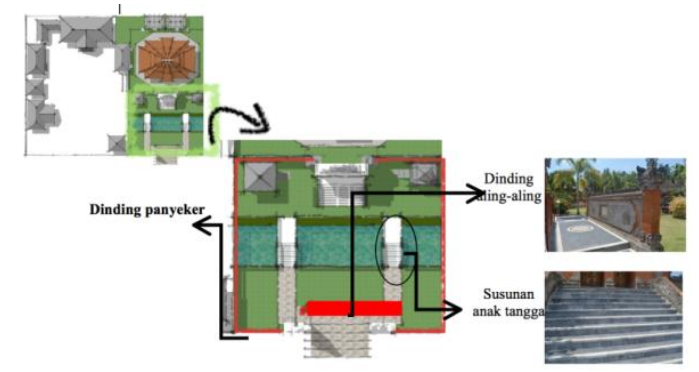

Gambar 4. Lansekap zona madya komplek gereja Kristen Pniel Blimbingsari, Bali

Sumber: Hasil Analisis, 2016 
Tabel 5. Analisis tata massa pada zona nista komplek gereja Kristen Pniel Blimbingsari, Bali

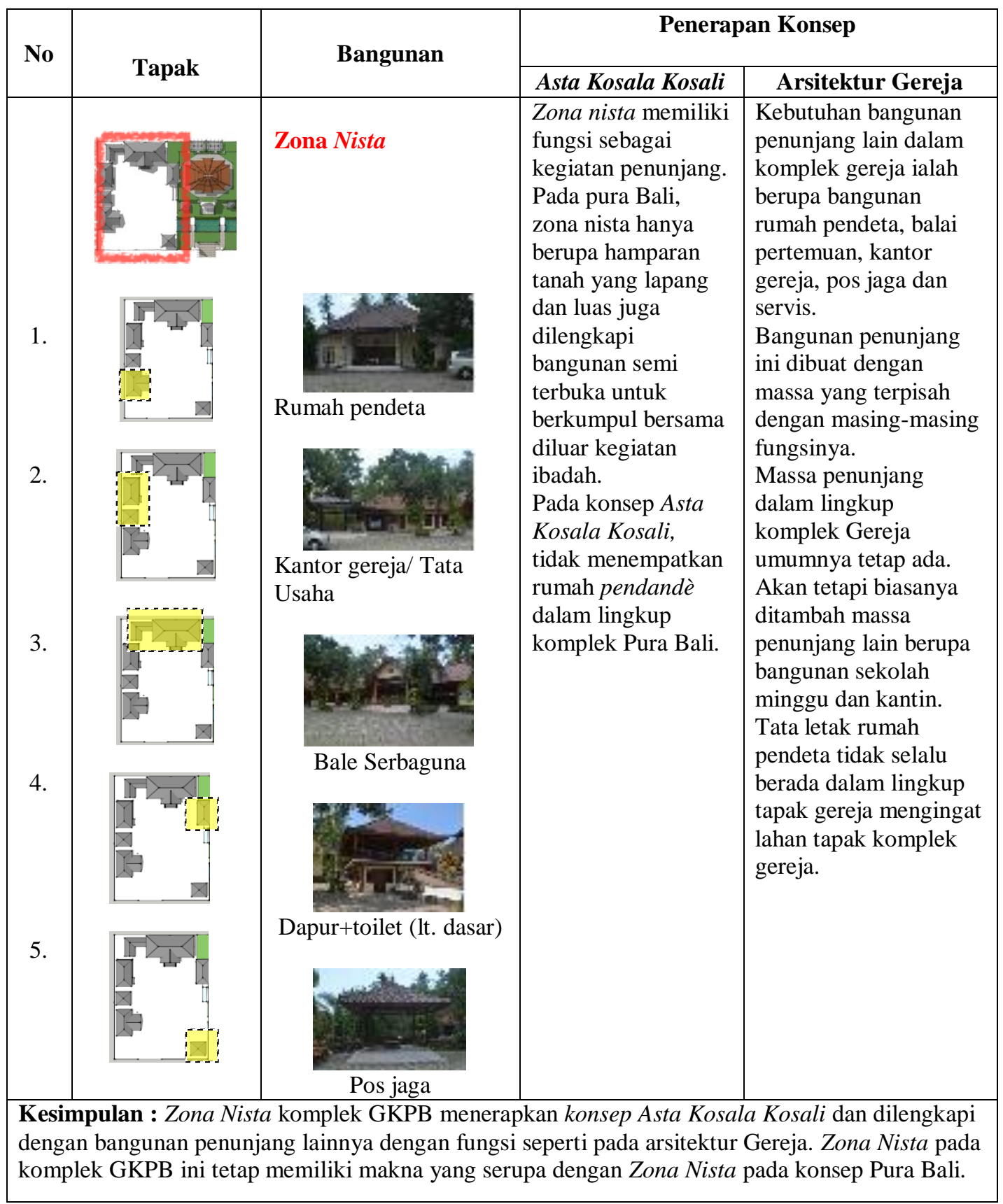

Sumber: Hasil Analisis, 2016

Letak Zona Nista pada komplek Gereja Kristen Pniel Blimbingsari ini berbatasan langsung dengan kedua Zona Utama dan Madya pada sisi kiri. Massa bangunan yang ada pada Zona Nista komplek GKPB sedikit berbeda dengan massa bangunan yang berada pada Zona Nista komplek Pura Bali. Hal ini mengingat kebutuhan akan penunjang massa gereja dan fungsinya. Perbedaan 
fungsi dan jumlah massa bangunan pada Zona Nista tidak serta merta menghilangkan esensi dari zona ini.

Massa bangunan dibagi berdasarkan tingkat kesakralannya juga sifatnya sebagai utama atau penunjang. Bangunan dengan fungsi utama untuk tempat ibadah yakni gereja juga ruang konsistori dan kesenian/ Bale goong ditempatkan pada Zona Utama. Zona Madya pada Komplek Gereja Kristen Pniel Blimbingsari merupakan zona perantara yang dipenuhi oleh tatanan lansekap dan dilengkapi dengan Bale Kul-Kul juga Bale Bengong. Fungsi lain berupa balai pertemuan, rumah pendeta, kantor gereja dan bangunan servis ditempatkan pada Zona Nista.

c. Bentuk arsitektur (fasad)

Bentuk massa bangunan atau sosok bangunan Gereja Kristen Pniel Blimbingsari dipengaruhi oleh arsitektur tradisional Bali, dalam hal ini bangunan Wantilan. Wantilan merupakan salah satu bangunan tradisional Bali. Secara keseluruhan, bangunan Gereja Kristen Pniel Blimbingsari memiliki bentuk yang mirip dengan Wantilan. Dalam bahasa Bali kuno Wantilan berarti balai terbuka. Wantilan dapat diartikan bangunan terbuka ke segala arah yang memiliki atap bertumpang.
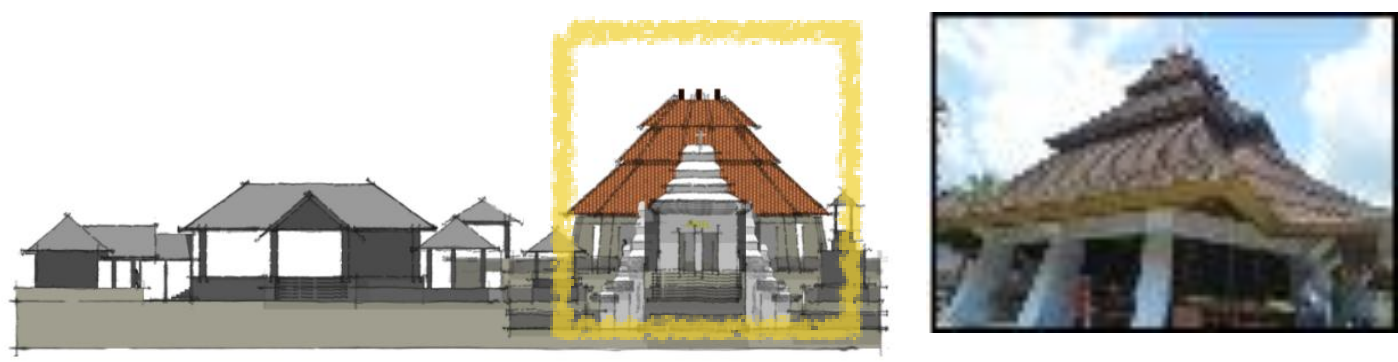

Gambar 5. Gereja Kristen Pniel Blimbingsari, Bali

Sumber: Hasil Analisis, 2016

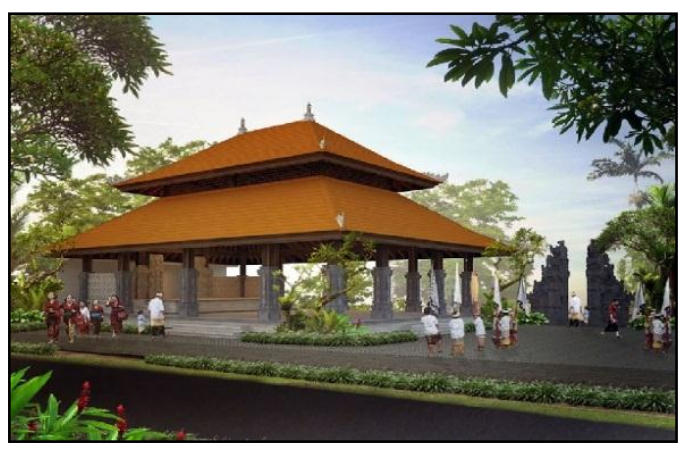

Gambar 6. Contoh wantilan

Sumber: Hasil Analisis, 2016

Bentuk arsitektur gereja tidak terlepas dari perlambangan agama Kristen dan hal lain yang mengedepankan skala Tuhan yang agung, sakral, suci, magis, dan religius pada keseluruhan arsitektur gereja. Gereja di awal kemunculannya, tidak memiliki pakem tertentu mengenai bentuk bangunannya.

Massa bangunan utama lainnya memiliki aplikasi ornamen tradisional Bali pada atap dan kolomnya. Fasad bangunan GKPB secara umum mengadopsi wujud arsitektur wantilan Bali tanpa mengubah makna yang terkandung di dalamnya. Hal ini terlihat dari penggunaan atap tinggi dan bertumpang, bersifat semi terbuka dengan kolom-kolom sekelilingnya, dan sebagai fasilitas publik. Konsep sebagai ruang ibadah bersama masih terasa dan menyatu dengan lingkungan sekitar. 


\section{d. Elemen arsitektur}

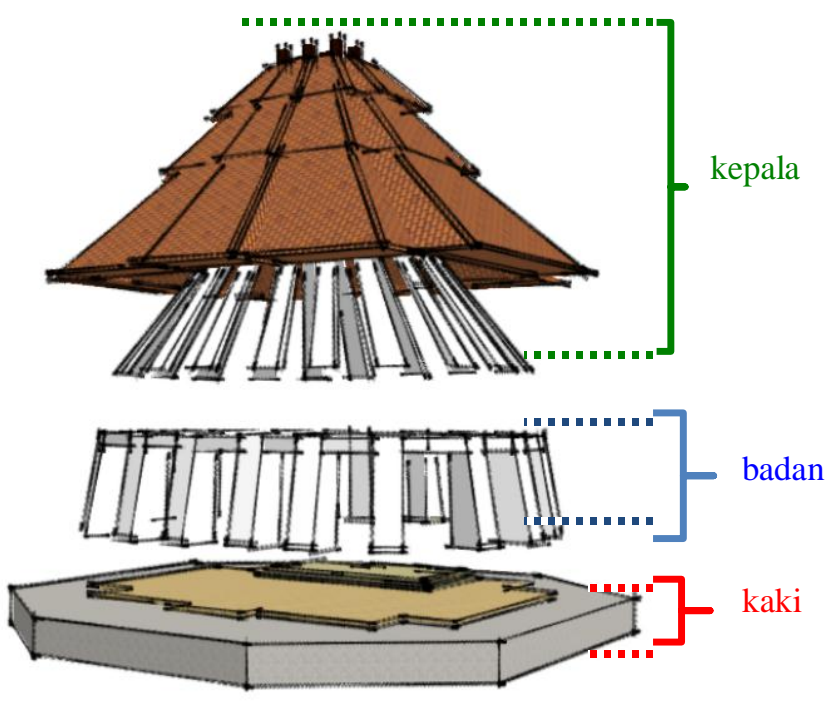

Atap bangunan bertumpuk tiga melambangkan konsep TriTunggal. Bahan atap menggunakan genteng tanah liat.

Bangunan bersifat semi terbuka dengan kolom berjumlah 18 buah tanpa ukiran khas Bali.

Denah lantai berbentuk segi delapan dengan penggunaan tiga anak tangga untuk mempertegas altar.

Gambar 7. Isometri terutai bangunan gereja Kristen Pniel Blimbingsari, Bali Sumber: Hasil Analisis, 2016

Tabel 6. Analisis elemen arsitektur komplek gereja Kristen Pniel Blimbingsari, Bali

\begin{tabular}{|c|c|c|c|}
\hline elemen & $\begin{array}{c}\text { Arsitektur } \\
\text { tradisional Bali } \\
\text { (Wantilan) }\end{array}$ & $\begin{array}{l}\text { Arsitektur GKPB, } \\
\text { Bali }\end{array}$ & Arsitektur Gereja \\
\hline Kepala & $\begin{array}{l}\text { Wantilan memiliki } \\
\text { bentuk atap yang } \\
\text { bertumpuk, bangunan } \\
\text { suci Meru pada pura } \\
\text { Bali memiliki atap } \\
\text { bertumpuk (ganjil) } \\
\text { untuk melambangkan } \\
\text { tingkat kesakralan. }\end{array}$ & $\begin{array}{lr}\text { Bangunan } & \text { GKPB } \\
\text { memiliki } & \text { atap } \\
\text { bertumpuk } 3 & \text { yang } \\
\text { melambangkan Bapa, } & \text { Batra, dan Roh Kudus. } \\
\text { Putra } & \text { Bentuk atap } \\
\text { mengerucut ke atas, } & \text { dibuat menjulang } \\
\text { tinggi dengan skylight } \\
\text { pada puncak atap. } \\
\text { Atap berkonstruksi } \\
\text { kayu. }\end{array}$ & $\begin{array}{l}\text { Tipikal bangunan } \\
\text { Gereja Kristen Lama } \\
\text { memiliki bentang } \\
\text { yang cukup lebar dan } \\
\text { lebih banyak } \\
\text { mengaplikasikan atap } \\
\text { pelana di Indonesia. }\end{array}$ \\
\hline
\end{tabular}




\begin{tabular}{|c|c|c|c|}
\hline Badan & $\begin{array}{l}\text { Bentuk Wantilan } \\
\text { adalah bujur sangkar } \\
\text { dengan struktur } \\
\text { rangka beratap yang } \\
\text { terbuka ke segala arah } \\
\text { tanpa adanya bidang- } \\
\text { bidang pemisah yang } \\
\text { tegas antara ruang luar } \\
\text { dengan ruang dalam. }\end{array}$ & $\begin{array}{lr}\text { Bangunan } & \text { GKPB } \\
\text { tidak } & \text { memiliki } \\
\text { dinding, melainkan } & \\
\text { hanya jajaran kolom } \\
\text { yang mengelilingi } \\
\text { denah ruang dalam } \\
\text { sebagai pemisah ruang } \\
\text { luar dan dalam. } \\
\begin{array}{l}\text { Jumlah kolom } 18 \\
\text { buah. }\end{array}\end{array}$ & $\begin{array}{lr}\text { Dinding } & \text { Gereja pada } \\
\text { umumnya memakai } \\
\text { metode konstruksi } \\
\text { dinding } \\
\text { beton/batu yaitu } \\
\text { diplester dan diberi } \\
\text { hiasan yang } \\
\text { tertentu. Jelas ada } \\
\text { pemisah antara ruang } \\
\text { luar dan dalam } \\
\text { (penggunaan dinding). }\end{array}$ \\
\hline Kaki & $\begin{array}{l}\text { Wantilan seperti pada } \\
\text { bangunan di komplek } \\
\text { pura lainnya memiliki } \\
\text { elevasi yang berbeda } \\
\text { (lebih tinggi) dari } \\
\text { permukaan tanah. }\end{array}$ & $\begin{array}{l}\text { Bangunan GKPB } \\
\text { hanya menaikkan } 10 \\
\mathrm{~cm} \text { dari permukaan } \\
\text { tanah asal di zona } \\
\text { utama. Melakukan } \\
\text { finishing dengan batu } \\
\text { sikat pada teras gereja } \\
\text { dan keramik pada } \\
\text { lantai ruang ibadah. }\end{array}$ & $\begin{array}{l}\text { Lantai Gereja pada } \\
\text { umumnya memiliki } \\
\text { elevasi yang lebih } \\
\text { tinggi dari permukaan } \\
\text { tanah asal. Akses } \\
\text { masuk gereja biasanya } \\
\text { diaplikasikan dengan } \\
\text { beberapa anak tangga. }\end{array}$ \\
\hline \multicolumn{4}{|c|}{$\begin{array}{l}\text { Kesimpulan : } \\
\text { Ketiga elemen yang dikupas pada bangunan GKPB, maka bangunan GKPB melakukan proses } \\
\text { adopsi dan adaptasi pada arsitektur tradisional setempat yakni Bali. Adapun dikenal dalam agama } \\
\text { Kristen yakni proses enkulturasi yakni perpaduan budaya tanpa menghilangkan pakem tertentu, } \\
\text { juga indegenesasi membaur dengan unsur setempat (Bali), dan kontekstualisasi terhadap } \\
\text { keseluruhan elemen bangunan GKPB terhadap budaya dan lingkungan setempat. }\end{array}$} \\
\hline
\end{tabular}

Sumber: Hasil Analisis, 2016

\section{e. Elemen arsitektur}

Secara keseluruhan bangunan Gereja Kristen Pniel Blimbingsari mengadopsi bentuk arsitektur Wantilan dengan penggunaan atap bertumpuk, jajaran kolom tanpa dinding dan berorientasi memusat. Kolom disusun berjajar mengelilingi denah ruang dalam tempat ibadah. Tipologi bangunan Wantilan menerapkan konsep pemisahan ruang luar dan ruang dalam tanpa penggunaan dinding pembatas.
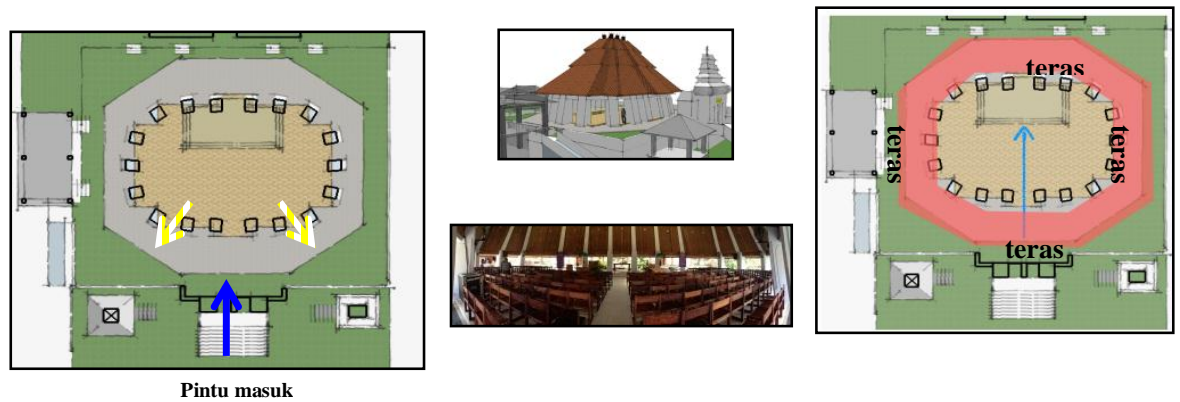

Gambar 8. Denah gereja Kristen Pniel Blimbingsari, Bali

Sumber: Hasil Analisis, 2016 
Ruang dalam bangunan GKPB secara umum mengadopsi wujud arsitektur Wantilan Bali tanpa mengubah makna/pakem tertentu gereja yang masih dipertahankan, yakni zona altar dan umat yang jelas juga penataan kursi jemaat yang mengikuti denah GKPB. Konsep sebagai ruang ibadah bersama masih terasa dan menyatu dengan lingkungan sekitar. f. Ragam hias (ornamen)

1) Dinding panyeker dan Dinding Aling-Aling (zona Madya)

Sekeliling Dinding Panyeker atau dinding pembatas komplek Gereja Kristen Pniel Blimbingsari terdapat ornamen ukiran khas Bali berupa flora atau disebut juga ornamen pepatraan Bali. Hal ini juga terjadi pada Dinding Aling-Aling, dinding dipenuhi oleh ukiran khas Bali berupa pepatraan Bali dilengkapi dengan batu ukiran perjanjian pada sisi depannya.
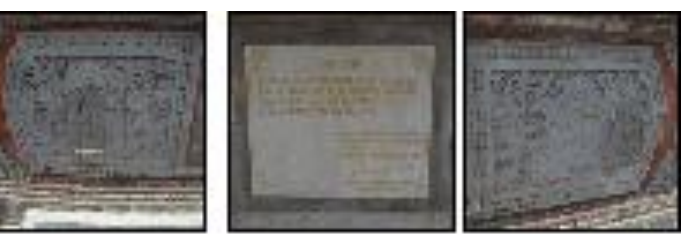

Gambar 9. Dinding panyeker (kanan) dan aling-aling (kiri) gereja Kristen Pniel Blimbingsari, Bali

Sumber: Dokumentasi Penulis, 2016

\section{2) Candi Bentar (Zona Madya)}

Candi Bentar dalam konsep Bali merupakan simbol mulut yang tenganga. Simbol mulut yang tenganga ini menjadikan Candi Bentar sebagai pintu masuk pada komplek Gereja Kristen Pniel Blimbingsari, Bali. Candi Bentar pada Gereja ini memiliki ornament salib sebagai simbol Agama Kristen.
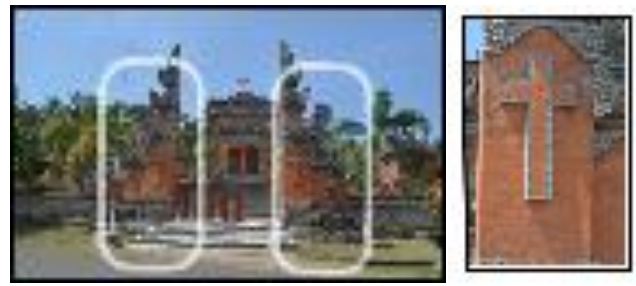

Gambar 10. Candi bentar gereja Kristen Pniel Blimbingsari, Bali

Sumber: Dokumentasi Penulis, 2016

\section{3) Kori Agung (zona Utama)}

Kori Agung ini berfungsi sebagai pintu masuk utama bangunan gereja. Bangunan Kori Agung memiliki dua celah untuk akses masuk. Kedua celah ini dihiasi oleh pintu beserta ukirannya yang memiliki makna tersendiri. Pada puncak Kori Agung juga terdapat ukiran salib yang menegaskan fungsi bangunan di dalamnya. Pada Kori Agung ini terdapat ukiran salib yang patah melambangkan posisi ketika Yesus di salib. 

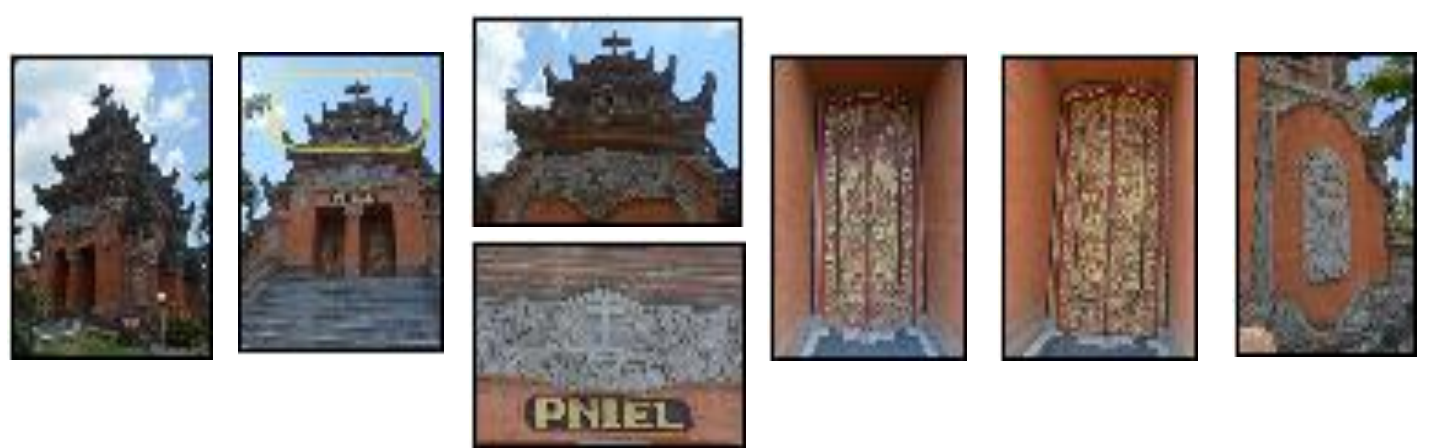

Gambar 11. Detail ornamen kori agung gereja Kristen Pniel Blimbingsari, Bali Sumber: Dokumentasi Penulis, 2016

Sosok massa Gereja Kristen Pniel Blimbingsari sendiri tidak memiliki ornamen pepatraan pada interiornya. Ornamen banyak diterapkan pada eksterior bangunan yakni pada Dinding Panyeker, Aling-Aling, dan bangunan khas tradisional Bali lainnya. Penggunaan material yang sama seperti bangunan tradisional Bali pada umumnya (batu paras dan bata merah). ruang luar bangunan GKPB secara umum mengadopsi detail ornamen khas Bali dengan menghilangkan Unsur Kala dan hanya menerapkan pepatraan flora Bali saja dilengkapi dengan ukiran salib pada bagian tertentu.

\section{Analisis Aspek Non-Fisik pada Arsitektur Gereja Kristen Pniel Blimbingsari, Bali}

Gereja Kristen Pniel Blimbingsari tidak mengalami perubahan dari fungsi liturgi keagamaannya. Sakramen, tata cara berdoa, baptis, hingga kelender liturgis merupakan rangkaian ritual keagamaan yang dilakukan Gereja Kristen Protestan lain pada umumnya. Tidak ada perbedaan dalam rangkaian ritual keagamaan secara umum.

Perbedaan terjadi pada beberapa hal dalam upacara kebaktian maupun perjamuan yang dilakukan Gereja Kristen Pniel Blimbingsari, Bali. Perbedaan ini hanya berupa implikasi dari budaya yang kental di pulau Bali tanpa mengubah makna yang terkandung dalam ritual keagamaan Gereja. Hal ini diaplikasikan oleh Gereja Kristen Pniel Blimbingsari dalam penggunaan pakaian untuk Jemaat, bahasa pengantar (bahasa Bali) dalam perjamuan dan kebaktian di hari tertentu, dan alunan musik khas Bali.

\section{Kesimpulan}

Dilihat dari hasil Analisa aspek fisik dan no-fisik Gereja Kristen Pniel Blimbingsari, Bali yang telah dilakukan, maka menghasilkan beberapa temuan, yaitu :

1. Konsep Asta Kosala Kosali dan Arsitektur Gereja secara signifikan mempengaruhi wujud arsitektur Gereja Kristen Pniel Blimbingsari, Bali. Kedua konsep ini saling berakulturasi membentuk suatu identitas baru bagi bangunan Gereja Kristen Pniel Blimbingsari, Bali.

2. Bangunan Gereja Kristen Pniel Blimbingsari mengadaptasi konsep Asta Kosala Kosali dimulai dari : 
orientasi tapak dan bangunan, tata massa bangunan berdasarkan zoning Tri Angga, fasad bangunan Gereja menyerupai Wantilan, elemen arsitektur secara keseluruhan mengadopsi konsep Wantilan, juga beberapa ragam hias pepatraan khas Bali terdapat di lansekap Gereja Kristen Pniel Blimbingsari, Bali.

Melalui telaah kasus studi, maka dapat disimpulkan bahwa konsep aristektur tradisonal Bali (Asta Kosala Kosali) memiliki peran yang dominan dalam membentuk Gereja Kristen Pniel Blimbingsari tanpa mengubah pakem liturgi dan kebutuhan pada fungsi suatu komplek Gereja Kristen Protestan. Aspek fungsi (kebutuhan ruang) sebagai bangunan ibadah umat Kristen tidak dapat diubah (bersifat bertahan) sedangkan aspek bentuk arsitektur bersifat adaptasi pada budaya lokal (bersifat berubah).

\section{Saran}

Idealnya sebagai seorang arsitek adalah perancang gubahan masa yang mengamalkan budaya setempat menjadi bagian dari dirinya, baik itu budaya asli daerahnya maupun budaya hasil akulturasi. Banyaknya budaya-budaya dari luar yang masuk ke dalam budaya arsitektur tradisional seharusnya menjadi tambahan ilmu budaya dalam kekayaan arsitektur tradisional Indonesia.

Arsitek sebagai tangan yang membentuk wajah, bentuk sebuah masa bangunan hingga wajah suatu wilayah seharusnya memiliki pemahaman yang mendalam mengenai karakter budaya setempat atau dimana bangunan yang dirancang akan didirikan, sehingga karya yang dihasilkan bukan hanya 'patung' semata melainkan memiliki makna mendalam dari sisi budaya arsitektur setempat.

\section{Daftar Pustaka}

Adimihardja, Kusnaka \& Purnama Salura. 2004. Arsitektur Dalam Bingkai Kebudayaan, CV Architecture and Communication, Bandung.

Ayub, I Ketut Suyaga. 2014. Blimbingsari : The Promise Land. Andi. Yogyakarta.

Dwijendra. Ngakan Ketut Acwin, 2008, Arsitektur Rumah Tradisional Bali Berdasarkan Asta Kosala-Kosali, Denpasar: Udayana University Press.

Fauzy, Bachtiar. 2011. Memahami Relasi Konsep Fungsi, Bentuk, Makna Arsitektur Rumah Tinggal Masyarakat Kota Pesisir Utara di Kawasan Jawa Timur. Jurnal Arsitektur vol 38.

GKPB Jemaat. 2010. Galang Ning Hyang Abianbase. Sejarah Gereja Bali-GKPB. Badung Bali.

Indrianto, Enrike Puspita. 2013. Akulturasi Pada Gereja Kristen Pniel Blimbingsari, Bali. Jurnal Intra vol 1 no 1 . Program Studi Desain Interior Universitas Kristen Petra.

K.W., Sukayasa. 2007. Gaya Eklektik pada Arsitektur Gereja Kristen Protestan Blimbingsari di Bali. Jurusan Seni Murni, fakultas Seni Rupa dan Desain, Universitas Kristen Maranatha. Bandung.

Suastika, Made. 2002. Wantilan Kuno di Sukowati Gianyar Bali (Penekanan pada Aplikasi Gegulak dan Maknanya), Tesis Arsitektur, UNDIP Semarang. 
Thiss, Evensen Thomas. 1987. Arhetypes in Architecture. Norwegian University Press. Oslo.

Wahyu, Sukayasa Komang. 2010. Gaya Eklektik pada Arsitektur Gereja. PT. Grasindo. Bandung. 